\title{
YKL-40 as a New Biomarker in Asthmatic Children and Asthmatic Exacerbation. Its Role and Correlations with Eosinophil's Percentage and Serum IgE Level
}

\author{
MAHMOUD M. ZAHRAN, M.D.*; EHAB IBRAHIM I. SOROUR, M.D.* and HESHAM S.M. ELBAZ, M.D.** \\ The Departments of Pediatrics* and Clinical Pathology**, Faculty of Medicine, Al-Azhar University
}

\begin{abstract}
Background: YKL-40 is a member of the mammalian chitinase like protein class of $40 \mathrm{Kda}$ (kilo Dalton) heparin binding glycoprotein. Its name is derived from the protein's molecular weight and three $\mathrm{N}$-terminus amino acids (tyrosine [y], lysine [k] and leucine [1]). YKL-40 is secreted by various cell-types including macrophages, chondrocytes, and some types of cancer cells. The exact physiological role of YKL40 is not known, but it has been implicated in cell development, inflammatory disease such as asthmaand cancer progression.

Aim of Study: This study was to investigate whether serum YKL-40 were increased in Asthmatic children and identify its correlation with acute exacerbation, total $\operatorname{IgE}$, blood Eosinophil percentage (EO\%) and Pulmonary Function (PF). We measured serum YKL-40 levels, EO\%, and serum IgE in 30 children with Asthma as well as in 20 apparently healthy controls from the communities surrounding AL-Salama Hospital, EL-Khobar district, Saudi Arabia. Pulmonary Function (PF) of Asthmaticpatients was also measured.
\end{abstract}

Patients and Methods: Our data showed that the serum YKL-40 was significantly elevated in patients with Asthma $(77.66 \mathrm{ng} / \mathrm{mL})$ compared with control $(55.16 \mathrm{ng} / \mathrm{mL})(p=0.001)$ and when Asthma patients were stratified, serumYKL-40 levels in exacerbation group were significantly higher $(83.72 \mathrm{ng} /$ $\mathrm{mL}$ ) than those in stable Asthmatic group (77.66ng/mL) $(p=0.043)$.

Results: In addition, serum YKL-40 was correlated positively with the level of $\operatorname{IgE}$ (with $r=0.298$ and $p=0.018$ ) and EO\% (with $r=0.272$ and $p=0.032$ ) but negatively correlated to pulmonary functions as Forced Expiratory Volumein 1 st second (FEV1) (with $r=-0.044$ and $p=0.0001$ ).

Thus, we conclude that YKL-40 is found significantly high in the serum of asthmatic childrenand its level correlates with exacerbation attacks, indicating that high levels of serum YKL-40 may be biological characteristic of the asthma exacerbation.

Conclusion: In our study, we conclude that serum YKL40 level are increased in asthmatic children patients and its level correlates with exacerbation attacks indicating that YKL-

Correspondence to: Dr. Mahmoud M. Zahran, The Department of Pediatrics, Faculty of Medicine, Al-Azhar University
40 may be either a cause or a new biomarker for asthma and its disease severity.

Key Words: YKL-4O - Asthmatic children-Astmatic excerbation - Serum IgE level.

\section{Introduction}

AIRWAY Hyper responsiveness (AHR) and reversible airway obstruction (RAO) are characteristic features of Asthma. Many Studies and researches are designed to evaluate and determine mechanisms of Asthma and how airway inflammation causes the disease and how to contribute to Asthma severity [1]

Recent studies focused on several mechanisms of airway inflammations, regulation of the immune responses by environmental factors, altered Allergens, injury-repair process (remodeling), inflammatory mediators as cytokines (INF y) from Th1 and IL5 from Th2 cells regarding to the balance between Th1/Th2 cell clones. Studies explained the importance of chemokines, IgE synthesis / production and processes contribute in the pathogenesis of asthma [2]

YKL-40 is a member of the mammalian chitinase like protein class of $40 \mathrm{kDA}$ (kilo Dalton) heparin binding glycoprotein. Its name is derived from the protein's molecular weight of three $\mathrm{N}$ terminus amino acids (tyrosine [Y], lysine $[\mathrm{K}]$ and leucine $[\mathrm{L}])$. The gene for YKL-40 has been identified on chromosome 1q31-q32). YKL-40 is also called [human cartilage glycoprotein39 (HCgp39)] or chitinase-3 like 1 (CH3L 1) binds chitin but it is deficient in chitinase activity. It is produced at sites of inflammation in many cells and is secreted by smooth muscle and Macrophage (Mo). YKL40 has been shown to be a potent growth factor for connective tissue cells and a potent migration factor for endothelial cells [3] 
Researches have demonstrated substantial levels of YKL-40 in environments with inflammation or where remodeling of the extracellular matrix (ECM) occurs. Previous studies have demonstrated that the expression level of YKL-40 was increased during T-helper (Th1) inflammatory cells [4]. Furthermore, it is suggested that YKL-40 has a role in inflammation and tissue remolding in human diseases as joint injury, liver fibrosis, type $2 \mathrm{DM}$ and cancer [5].

As current concepts of pathogenesis of Asthma, it is the result of exaggerated Th2 airway inflammation, airway remolding's role in the pathological features of asthma, and YKL-40 is believed to have a role in the pathogenesis of asthma and attracts the attention of many collaborative groups. Recent study of Chupp, et al., 2007 established that YKL40 level were increased in lung and circulation of patients suffered from severe Asthma [6].

YKL-40 level predominantly increased at the site of allergen deposition in response to allergen challenge. Whether, YKL-40 is stable or more increased during exacerbations of asthma [7].

\section{Patients and Methods}

\section{Study design and subjects:}

30 Asthmatic childrenaged 6-16 years were selected from Al-Salama Hospital, Al-Khobar City over period between March and December, 2012. Asthmatic group was divided into two subgroups (15 for each stableand exacerbation). The diagnosis of Asthma was based on established guidelines [8] 20 apparently healthy children with the same age group without allergic manifestations were encountered as control group.

\section{Exacerbation group:}

15 Asthmatic patients who requested urgent medical care for an acute exacerbation of Asthma were recruited for the exacerbation group after presentation to a clinic or emergency room. Acute exacerbation of Asthma was defined asepisodes of a rapidly progressive increase in a shortness of breath, cough, wheezing or chest tightness or a combination of these symptoms necessity a nonscheduled visit associated with a decrease in respiratory airflow quantified by measurements of (FEV1) [8].

In our study, Asthmatic patients with exacerbation were enrolled only when (FEV 1) was $<80 \%$ of the predicted value.

\section{Exclusion criteria:}

We excluded from this study patients who had concomitant diseases proved to be related to YKL40 as DM, rheumatoid arthritis, hepatic fibrosisor had pneumonia within the preceding 4 weeks from the study. Blood samples from the exacerbation group were collected within 6 hour after the medical visit.

\section{Stable group:}

15 age matched patients with stable Asthma were recruited during their scheduled clinic visit. Their symptoms and (FEV 1) were stable. The enrolled patients experienced no change in their treatment course for at least 4 weeks and had no evident asthma exacerbation during that time period.

Our study was approved by the human investigations committee at our institution at Al-Salama Hospital. All groups gave written informed consent.

Blood sample of was collected from both asthmatic group and control group which divided into two tubes, one with EDTA for CBC and EO\% and the other for serum IgE and serum YKL-40 assay.

\section{Measurement of serum IgE level and YKL-40: IgE assay:}

$1 \mathrm{ml}$ of clotted blood sample was collected for determination of Serum IgE. This fluorescent enzyme immunoassay (FEIA) measures total and allergen-specific immunoglobulin E (IgE) in human serum. The technique used for this test is (Immuno CAP, Phadia AB, Uppsala, Sweden). Results of this procedure is rapidly available [9] USA):

Serum YKL-40 level: (Quidel, San Diego, CA,

$1 \mathrm{ml}$ of clotted blood samples was collected for the determination ofYKL-40 level. ELISA (enzyme-linked immunosorbent assay) is a widelyused application for the detection of YKL-40 assay in a microwell format. This assay requires the use of an antibody labeled with a tag such as peroxidase or phosphatase, and an enzymatic substrate that produces a visible signal, indicating the presence of the Allergen. Signal levels are measured in a spectrophotometer. In a properly optimized assay, the intensity of the signal generated is proportional to the amount of Allergen present [10]

Calculation of the result: The standard curve for the YKL-40 EIA Kit is generated using the A405 values for each Standard (on the Y axis) and the assigned concentration for each YKL-40 Standard (on the $\mathrm{X}$ axis). The data will be graphed 
manually and the values $(\mathrm{ng} / \mathrm{mL})$ of the test specimens will be read directly from thebest-fit line of the Standard Curve.

Interquartile Range (IqR) for children(male / female) was $60.25 \mathrm{ng} / \mathrm{mL}$ while its Median range was (45.75- 87.0) and for control group (IqR) was 55.16 and its Median range was (34.23-70.75ng/ $\mathrm{mL}$ ). The minimum detection limit is $20 \mathrm{ng} / \mathrm{mL}$ from ELISA kits [11].

Analysis was performed using SPSS software, version 13.0 (SPSS, Chicago IL., USA). YKL-40 levels were not normally distributed and the values were compared among the study groups with the use of non-parametric tests, including the (MannWhitney U-test and the Kruskal-Wallis H-test). YKL-40 level were expressed as Median and interquartile range (IqR).

Simple association between YKL-40 levels and total IgE, EO\% and pulmonary function (PLF) were assessed using Spearman's rank correlation analysis.

\section{Results}

In our study, we measured the level of serum YKL-40 in 30 asthmatic children divided into two subgroups, stable [ 15 children, 8 boy/7 girl] and exacerbation [ 15 children, 10 boy $/ 5$ girl] and control group of non-asthmatic apparently normal children [20 children 12 boy/8 girl] from the same community near to Al-Salama Hospital, El-Khobar district, Saudi Arabia and compared the findings of the exacerbation group with those from the stable group and controls. Furthermore, the relationships between serum YKL-40, IgE, EO\% and pulmonary function $(\mathrm{PF})$ were investigated.

The characteristics of patients and controls are shown in (Table 1).

There were significant statistical differences between asthmatic and control groups as regard percentage of Eosinophils (EO \%), serum IgE. Compared with patients in the stable group, those with exacerbation group had more severely compromised pulmonary function (PF) (Table 1).

Table (1): The characteristics of patients and control in the study.

\begin{tabular}{lllllll}
\hline Characteristic & All & Control & Stable & Exacerbation & $\begin{array}{c}\text { Control vs. } \\
\text { all patient } \\
(p \text {-value })\end{array}$ & $\begin{array}{c}\text { Stable vs. } \\
\text { Exacerbation group. } \\
(p \text {-value })\end{array}$ \\
\hline Number of patients & 50 & 20 & 15 & 15 & & \\
Age (Years) & $10.1 \pm 4.2$ & $9.8 \pm 6.3$ & $7.4 \pm 4.6$ & $8.1 \pm 3.6$ & 0.41 & 0.06 \\
Male to Female ratio & $30 / 20(1.5: 1)$ & $12 / 8(1.5: 1)$ & $8 / 7(1.14: 1)$ & $10 / 5(2: 1)$ & 0.4 & 0.1 \\
IgE $(\mathrm{kU} / \mathrm{L})$ & $506.3 \pm 44.1$ & $131.5 \pm 87$ & $420.5 \pm 255$ & $536.1 \pm 41$. & $<0.001$ & 0.484 \\
EO $\%$ & $5.29 \pm 4.33$ & $2.9 \pm 1.4$ & $5.26 \pm 1.93$ & $5.3 \pm 4.3$ & 0.001 & 0.26 \\
FEV 1/FVC & & & $0.96 \pm 0.05$ & $0.68 \pm 0.1$ & & $<0.001$ \\
\hline
\end{tabular}

Data are represented as mean \pm SD unless otherwise stated IgE, EO\% (eosinophil \%).

FEV1,FVC: (Forced expiratory volume in 1st second/ forced vital capacity).

Continuous data were compared using Kruskal-wallis and categorical data were compared using Pearson's on chi-squared test.

There were significant statistical differences for percentage of Eosinophils between the control group $(2.9 \pm 1.4)$ and patients with stable asthma $(5.29 \pm 4.33)$ and for exacerbation group $(5.3 \pm 43)$ with a $p$-value for control versus to all $(p=0.001)$ and for stable versus exacerbation group was $(p=0.26)$.

There were significant differences as regard $\operatorname{IgE}$ between the control group $(131.5 \pm 0.87)$ and both patients groups (stable \& Exacerbation) with Asthma. There were significant differences between stable group $(420.5 \pm 255)$ versus exacerbation group $(536.1 \pm 41.0)$ with a $p$-value $(p=0.484)$. Statistical difference between control group versus both asthmatic groups was significant ( $p=0.001)$.
YKL-40 levels in patients with Asthma were higher than those in control. Interquartile range (IqR) for Asthma group was 60.25 with median (45.75-87.0ng/mL) versus control IqR was 55.16 with median (34.23-70.75ng/mL) with a $p$-value $(p=0.003)$ (Fig. 1A).

When the relationship between YKL-40 level of both asthmatic groups and those of control group were evaluated, we found that the YKL-40 level for patients in the exacerbation group were significantly higher than those in the control group with IqR $83.72 \mathrm{ng} / \mathrm{mL}$ and median $(47.0-97.25 \mathrm{ng} / \mathrm{mL})$ versus IqR $55.16 \mathrm{ng} / \mathrm{mL}$ with median (34.23-70.75 $\mathrm{ng} / \mathrm{mL})$ and a $p$-value $(p=0.001)$, and those in the stable group, IqR was 83.72 with median (47.0- 
$97.25 \mathrm{ng} / \mathrm{mL}$ ) versus IqR $60.25 \mathrm{ng} / \mathrm{mL}$ with median $(39.0-72.75 \mathrm{ng} / \mathrm{mL})$ and a $p$-value $(p=0.043)$.

YKL-40 levels in patients in exacerbation group were significantly higher than those in stable group

Fig. (1): Serum YKL-40 levels in asthmatic patients and controls.

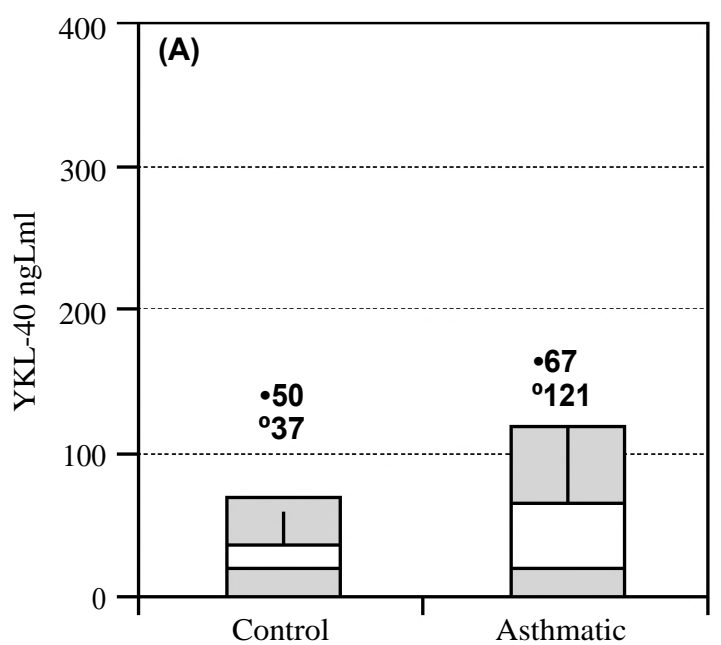

with IqR83.72ng/mL with median (47.0-97.25 $\mathrm{ng} / \mathrm{mL}$ ) versus those in stable patient group IqR was $60.25 \mathrm{ng} / \mathrm{mL}$ with median $(45.75-78.0 \mathrm{ng} / \mathrm{mL})$ (Fig. 1B).

Fig. (1): Serum YKL-40 levels in asthmatic patients and controls. The levels of circulating YKL-40 were assessed in patients with asthma and controls. (A) The serum YKL-40 levels in patients with asthma were higher than those in controls. (B) When patients were stratified according to exacerbation attacks, the serum YKL-40 levels in patients in the exacerbation group were higher than those in the control group and those in the stable group. Data are presented as median (horizontal line in each box), with 25 th and 75 th percentiles (top and bottom of each box) and 10 th and $90^{\text {th }}$ percentiles (top and bottom of each bar) and outliers ( ${ }^{\circ}:>3$ quartile deviations; $\bullet:>6$ quartile deviations). \#: $p=0.003$; $* * *: p=0.001 ; \mathbb{I}: p=0.043$.

Fig. (2): Correlation of serum YKL-40 levels with several associated items ((IgE) levels and the percentage of peripheral blood eosinophils.

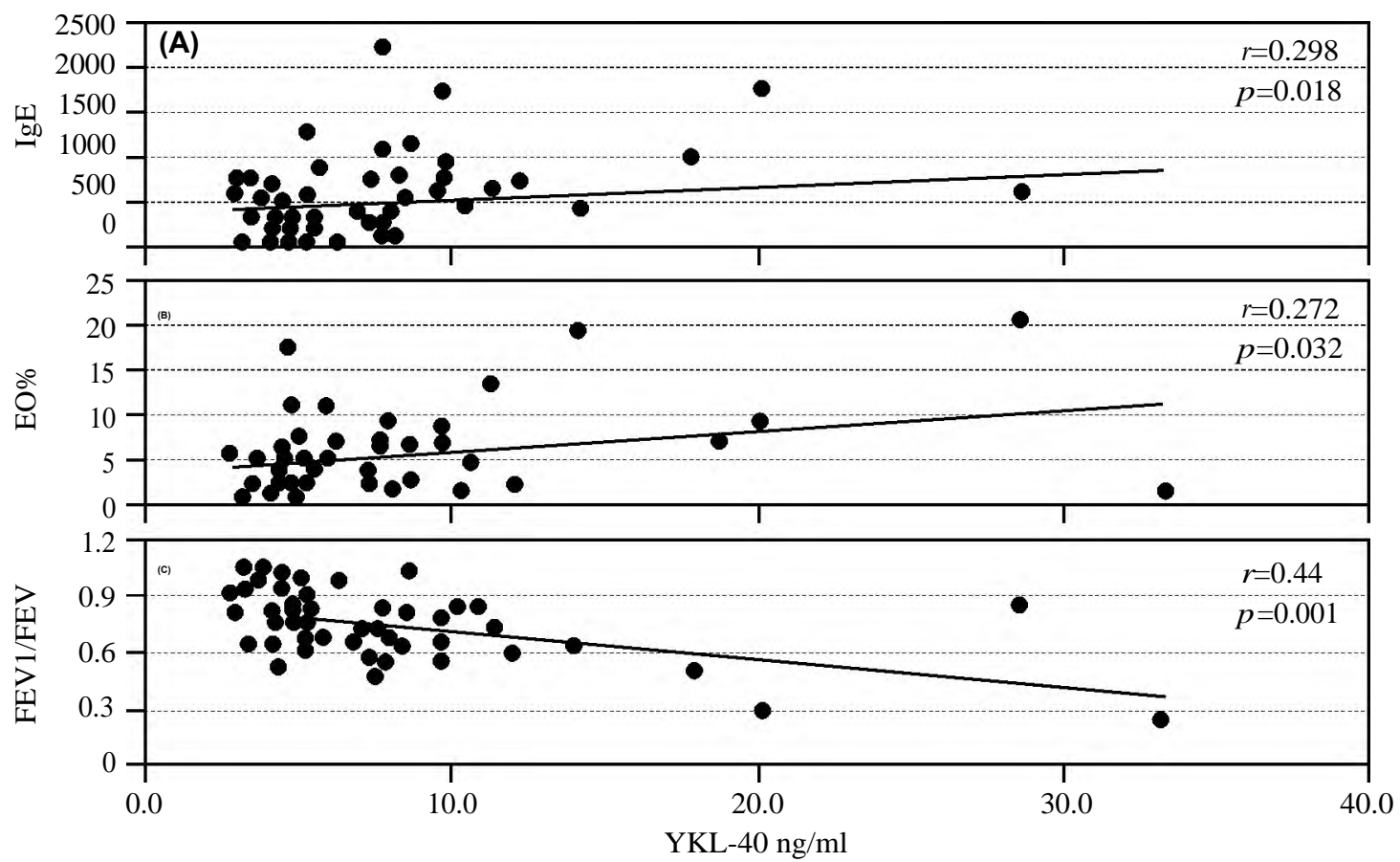

Fig. (2): Correlation of serum YKL-40 levels with several associated items. Spearman's rank correlation analysis showed a significant correlation between the serum YKL-40 levels. (A) The total serum immunoglobulin Elevels (IgE) $(r=0.298$, $p=0.018)$; (B) The percentage of peripheral blood eosinophils $(r=0.272, p=0.032)$; (C) Forced expiratory volume in $1 \mathrm{~s}($ FEV1)/predicted value $(r=-0.44, p=0.001)$. 
In patients with asthma, the correlation between Serum YKL-40 levels, IgE, EO\% and the ratio of prebronchodilator (FEV 1) to the predicted value were investigated. The findings revealed that Serum YKL-40 levels correlated with IgE levels ( $r=0.298$, $p=0.018)$ (Fig. 2A), The EO $\%(r=0.272, p=0.032)$ (Fig. 2B) and the ratio of (FEV1) ( $r=-0.044$, $p=0.0001$ ) (Fig. 2C).

\section{Discussion}

Chitin, a polymer of $\mathrm{N}$-acetyl glucosamine, is the second most abundant polysaccharide in nature. It is found in the walls of fungi; the exoskeleton of crabs, shrimp and insects, the micro-filarial sheath of parasitic nematodesand the lining of digestive tracts of many insects [12]

Chitin accumulation is regulated by the balance of chitin synthase-mediated biosynthesis and degradation by chitinase [13]

Elevated circulating YKL-40 levels were proved to be present in patients with meningitis, pneumonia, Rheumatoid arthritis and hepatic fibrosis [14]

Furthermore, Chupp have demonstrated that YKL-40 is strongly up-regulated in the airway epithelium \& alveolar macrophages of patients with Asthma and serum YKL-40 levels are elevated in patient with Asthma. Circulating YKL-40 levels are correlated with Asthma severity. The thickness of the sub-epithelial basement membrane and pulmonary function suggesting that circulating YKL40 levels are a biomarker for Asthma [6]. Additionally, YKL-40 concentrations increased in response to Allergen challenge predominantly at the site of Allergen deposition [7]

Our study manifests that in children aging from 6-14 years, circulating levels of YKL-40 are increased in patients with asthma compared with healthy children. When the asthmatic patients were categorized, circulating levels of YKL-40 in the exacerbation group were higher than those in the stable and healthy children groups which suggest that serum YKL-40 levels correlate with asthma exacerbation attacks. In addition, the serum levels YKL-40 correlate positively with serum IgE levels and $\mathrm{EO} \%$ and correlate negatively with pulmonary function.

Our data showing the comparison of serum YKL-40 levels between asthma and healthy children, and the correlation between the protein levels and lung functions coincide with those from the study by Chupp, et al., 2007 [6]. Another study by Sohn, et al., 2009 suggested that in the East Asian children, there is no significant associations between YKL-40 single nucleotide polymorphism (SNPs) and asthma are observed, while a (SNPs) was found to be associated with atopy and serum YKL-40 levels [15]. Although this study did not compare serum YKL-40 levels of asthmatic children with those of healthy control children directly, the basis for this potential discrepancy may be due to the differences in the mean ages of these children, since some children with atopy may develop asthma with increasing age.

In our Study, we showed that during exacerbation attacks, serumYKL-40 levels of patients with Asthma are higher than those of the stable group and healthy children, and illustrated the protein's correlations with $\mathrm{IgE}$ and $\mathrm{EO} \%$ among asthmatic patients. However, perspective studies will be required in order to determine whether serum YKL40 would decline when those exacerbations children are completely controlled after treatments; this is the aim of our further efforts. Although the pathogenic role of YKL-40 in Asthma remains unclear, our study indicates that the high levels of YKL40 may be a biological characteristics of Asthma exacerbation.

\section{Recommendations:}

Future researches are recommended to determine how airway inflammatory activity causes and contributes to disease severity. Furthermore, as molecules contributing to the regulation of airway inflammation are discovered, the role of cytokines and their balance in the development and evolution of disease will be important to understand asthma persistence and severity.

Also we recommend further studies to follow the levels of YKL-40 after improvement of exacerbation activity to confirm the relation of YKL40 with the disease activity.

\section{References}

1- BRANNAN J.D.: Bronchial hyper responsiveness in the assessment of asthma control: Airway hyper responsiveness in asthma: Its measurement and clinical significance. Chest, 138: 11S-17S, 2010.

2- DOUGHERTY R.H., SIDHU S.S., RAMAN K., SOLON M., SOLBERG O.D., CAUGHEY G.H., et al.: Accumulation of intraepithelial mast cells with a unique protease phenotype in $\mathrm{T}(\mathrm{H}) 2$-high asthma. J. Allergy Clin. Immunol., 125: 1046-1053.e1048, 2010.

3- RATHCKE C.N., JOHANSON J.S. and VESTERGUARD H.: YKL-40, a biomarker of inflammation is elevated in patients with type $2 \mathrm{DM}$ and is related to insulin resistance. Inflamm Res., 66: 53-59, 2006.

4- LEE C.G. H.R., LEE G.R. and FLAVELL R.A.: Generation and use of breast regression protein (BRP) -39 null 
mice to define the roles of (BRP) - 39 in Th2 inflammation and IL13 induced inflammation and remolding. Am. J. Res. Crit. Care Med., 175: A253, 2007.

5- JOHANSON J.S., JENSEN H.S. and PRICE P.A.: A new biochemical marker for joint injury. Analysis of YKL-40 in serum and synovial fluid. Br. J. Rheumatol., 949-955, 2003.

6- CHUPP G.L., LEE C.G. and JARJOUR N.A.: Chitinase like protein in the lung and circulation of patients in severe asthma. N. Engl. Med., 357: 2016-2027, 2007.

7- KUEPPER M., BRAKE K. and VIRCHOW G.C.: Chitinase like protein and Asthma. N. Engl. Med., 358: 10731075,2008

8- Global initiative for Asthma (GINA): Global Strategy for Asthma Management and Prevention. http://ginaasthma. . org/date last accessed:, 2011.

9- HOLGATE S. and LACK G.: Improving the management of atopic disease. Arch. Dis. Child, 90: 826-831, (2005.

10- LEUNG T.F., WONG G.W. and KO F.W.: Clinical and Atopic parameters and airway inflammatory markers in child. od Asthma: A factor analysis. Thorax, 822-826, 2005.

11-De MARCO R., MARCON A. and JARVIS D.: Prognostic factors of Asthma severity: 9 years international prospective coanortstudy. J. Allergy Clin. Immunol., 117: 12491256, 2006.

12- SHIBATA Y., FOSTER L.A. and BRADFIELD J.F.: Administration of chitin down-regulates serum $\operatorname{IgE}$ and Lung Eosinophilia in Allergic Mouse. J. Immunol., 13141321, 2010.

13- ZHU Z., ZHENG T. and HOMER R.I.: Acidic mammalian chitinase in Asthmatic Th2 inflammation and IL13 pathway activation. Science, 304: 1678-1682, 2004.

14- JOHNSON J.S., WILLIAMSON M.K. and RICE J.S.: Identification of protein secretion by human oesteoblastic cells in culture Bone Miner Res., 7: 501-512, 2007.

15- SOHN M.H., LEE J.H. and KIM K.W. GENETIC: Variation in promoter region of chitinase-3 like is associated with Atopy. Am. J. Res. Crit. Care Med., 179: 449-456, 2009. 


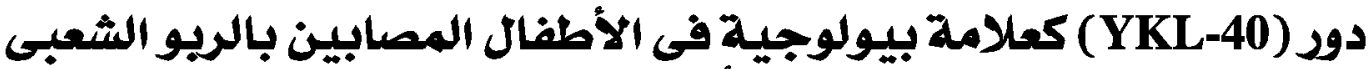

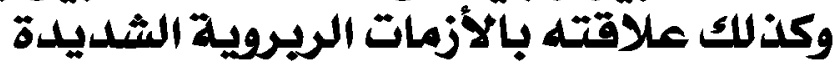

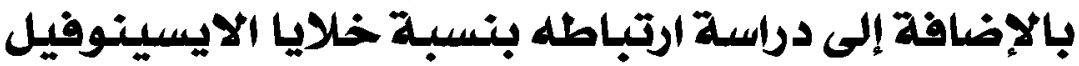

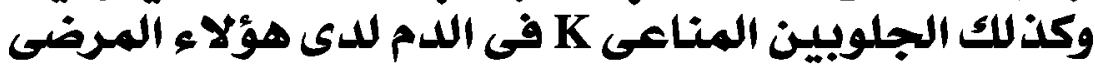

ملخص الدراسة: (YKL-40) عبارة عن بروتين ثلاثى النهايات شبيه بالكيتينيز لدى الثييات وتكمن أهميته في أنها ما أن يكون السبب

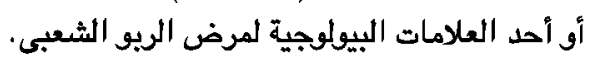

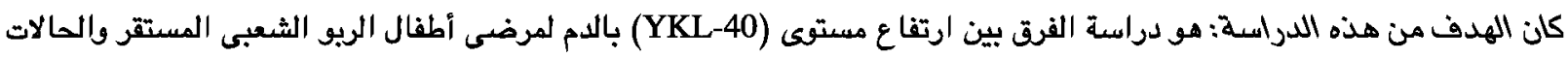

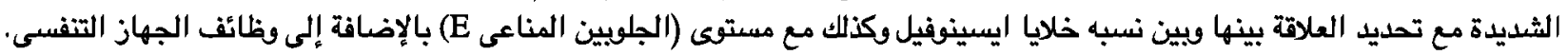

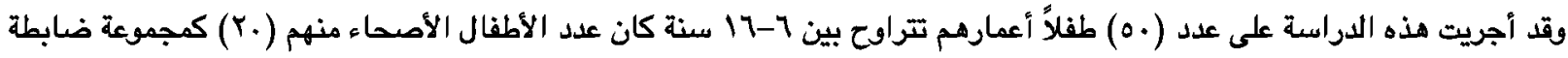

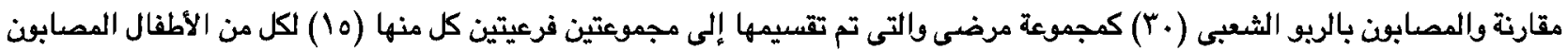

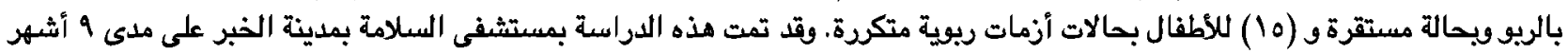

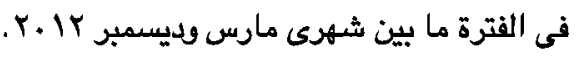

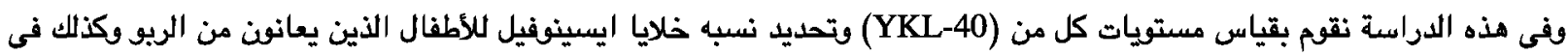

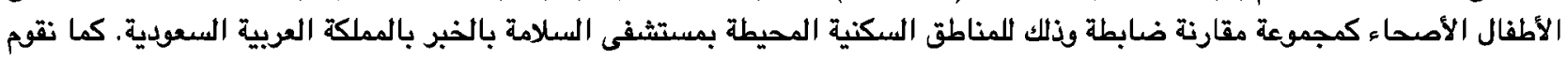
كنلك بقياس وظائف الجهاز التنفسى لمجموعتى المرضى.

وأظهرت نتائج البحث أن هناك ارتفاع ذو دلالة إحصائية لمستوى (YKL-40) فى الأطفال المرضى المصابون بالريو الريو الشعبى معطياً مؤشراً

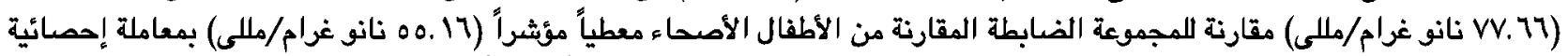

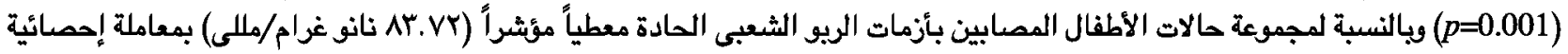

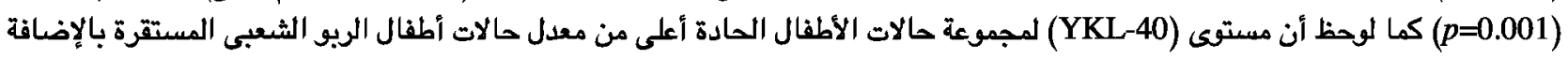

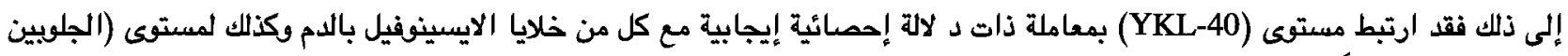

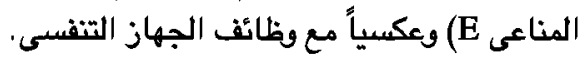

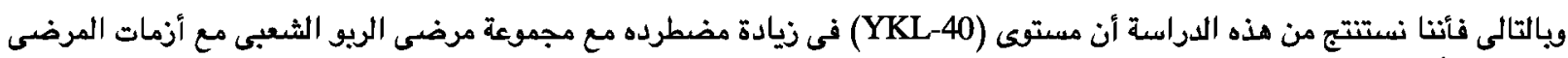

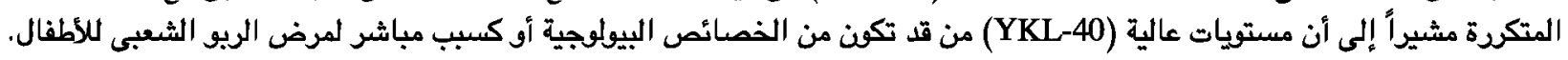
كذلك توصى هذه الدراسة بعمل دراسات أخرى تعمل على متابعة مستويات (YKL-40) بعد استقرار حالة المرضى لدعم النتائج السابقة

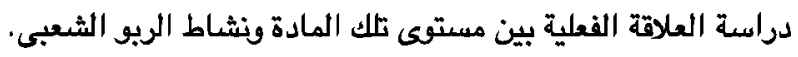

